\title{
Correction to: The Role of the Substrate on Photophysical Properties of Highly Ordered 15R-SiC Thin Films
}

\author{
SATYENDRA MOURYA, ${ }^{1,2}$ JYOTI JAISWAL,${ }^{1}$ GAURAV MALIK, ${ }^{1}$ \\ BRIJESH KUMAR, ${ }^{2}$ and RAMESH CHANDRA ${ }^{1,3}$ \\ 1.-Thin Film Laboratory, Institute Instrumentation Centre, Indian Institute of Technology \\ Roorkee, Roorkee 247667, India. 2.-Department of Electronics and Communication Engineering, \\ Indian Institute of Technology Roorkee, Roorkee 247667, India. 3.—e-mail: ramesfic@iitr.ac.in
}

\section{Correction to:}

Journal of ELECTRONIC MATERIALS,

Vol. 47, No. 9, 2018

https://doi.org/10.1007/s11664-018-6411-6

The wrong issue and volume number are indicated on the published article. This article appears in Volume 47, Number 9. 